Article

\title{
Photoreceptor PhyB Involved in Arabidopsis Temperature Perception and Heat-Tolerance Formation
}

\author{
Junyi Song ${ }^{1, \dagger}$, Qijun Liu ${ }^{1,+}$, Biru $\mathrm{Hu}^{1, *}$ and Wenjian $\mathrm{Wu}^{1,2}$ \\ 1 College of Science, National University of Defense Technology, Changsha 410073, China; \\ songjunyi@nudt.edu.cn (J.S.); ivanliuqj@nudt.edu.cn (Q.L.); wjwu67@nudt.edu.cn (W.W.) \\ 2 State Key Lab of Nuclear, Biological and Chemical Protection for Civilian, Beijing 102205, China \\ * Correspondence: hubiru08@nudt.edu.cn; Tel.: +86-0731-84574245 \\ + These authors contributed equally to this work.
}

Academic Editor: Hikmet Budak

Received: 17 February 2017; Accepted: 31 May 2017; Published: 5 June 2017

\begin{abstract}
The influence of temperature on plants is essential. However, our knowledge on the intricate regulation process underlying heat stress (HS) response in plants is limited. Recently, information about thermal sensors in vivo has begun to emerge. In this study, another primary environmental stimulus, light, was verified once again to work with temperature synergistically on plants, through the modulation of numerous biological processes. With the application of transcriptomic analysis, a substantial number of heat-responsive genes were detected involved in both light- and phytohormone-mediated pathways in Arabidopsis. During this process, phytoreceptor phyB acts as a molecular switch to turn on or turn off several other genes HS response, under different light conditions. Furthermore, a morphological study showed the afunction of phy $B$ enhanced plants thermal tolerance, confirming the important role of this phytochrome in temperature perception and response in plants. This study adds data to the picture of light and temperature signaling cross-talk in plants, which is important for the exploration of complicated HS responses or light-mediated mechanisms. Furthermore, based on its influence on Arabidopsis thermal response in both morphological and physiological levels, phyB is a photoreceptor, as revealed before, as well as an essential thermal sensor in plants.
\end{abstract}

Keywords: Arabidopsis thaliana; heat stress response; transcriptomic and morphological analysis; photoreceptor-phyB; interplay between abiotic stresses

\section{Introduction}

With relatively weak mobility, plants have to adjust their physiological and metabolic processes according to their surroundings [1]. Light and temperature are two major environmental factors influencing plant growth and development substantially [2-4].

As an energy and stimulus source, light codes information into its quantity (fluence), quality (wavelength), direction, and duration, providing plants with spatial, temporal, and seasonal clues. Thus, plants can regulate multiple developmental processes throughout their lifecycle-about when to sprout, flower, and settle seeds [5]. It is relatively clear about how plants perceive light changes and transmit these signals [6]. For example, phytochromes and cryptochromes act as regulators of germination [7], flowering and hypocotyl elongation [8] according to red/far red and blue light conditions.

On the other hand, temperature is a key parameter influencing the metabolism and cell functions of living beings [9-11]. The impacts of temperature change are determined by intensity, duration, 
and rate [12]. Ambient temperature provides plants with clues about when to dormant, germinate, and swift from the vegetative growth stage to the reproductive stage [13]. However, because the responses to temperature are systematic and extremely complicated [14], our knowledge about temperature sensors in plants is quite limited [15].

For quite a long period, these two factors have been studied separately. However, physiological processes in plants are influenced by synergistic effects of multiple surrounding signals [16-18]. As two ubiquitous environmental factors, light and temperature work simultaneously [19] to regulate plant germination [20,21], flowering, and reproduction [22,23]. Studies have already indicated a tight relationship between light and temperature signaling pathways in plants $[24,25]$.

Recently, more direct evidence has been found. By chasing the formation of the phyB nuclear body, Martina Legris et al. verified that phytochrome responds to both light and temperature stimulations [26]. Jae-Hoon Jung et al. reported that plant heat stress (HS) response can be altered in both transcription and morphology levels by knocking out the function of phytochrome [27].

By adopting different approaches, consistent discoveries are presented in this paper. Firstly, the expression of a substantial number of genes was detected to be activated or depressed after being treated with high temperature stress. This global monitoring identifies most HS responsive molecular elements in plants, providing us with a cornucopia of thermal sensor investigation.

Bioinformatics analysis was performed to decode the data. It revealed that various essential factors involved in plant light-signaling pathways and phytohormone-metabolic processes responded to the HS treatment. Therefore, based on the transcriptomic data acquired in this study and the information collected by bioinformatics approaches, an exciting blueprint shows that light and temperature perception pathways in plants are integrated. Meanwhile, these two signaling cascades converge and deliver messages to each other by the coordinated regulation of phytohormone metabolism.

Moreover, the bioinformatics analysis of microarray data inspired us to pay attention to the performance of photoreceptor phyA and phyB in plant HS response. It was assumed that, if these two phys participated in this process, the HS response in plants could be modified by photostimulation. In consideration of this, we pioneered the detection of transcriptional response to HS under different light conditions. The outcome of this assay revealed that light was an essential incentive, which adjusted the HS response in plants by regulating the active states of phys.

Furthermore, morphological observations on phytochrome null plants were conducted. Although Jae-Hoon Jung has already accomplished similar experiments, we are the first to report the influences of HS in Arabidopsis lateral root development. The observation on phyB mutants shows that the afunction of this photoreceptor diminished the HS effects on lateral root development and increased the survival rate of plants after HS treatment.

\section{Results and Discussion}

\subsection{Microarray Analysis of col-0 under Heat Stress}

Genome scale transcriptional analysis is essential for abiotic stress response studies in plants $[12,15,28,29]$. The microarray successfully detected the significant HS response in plants, with 1852 differentially expressed genes (see Table S1) between control $\left(23^{\circ} \mathrm{C}\right)$ and HS-treated groups $\left(37^{\circ} \mathrm{C}\right)$. To determine their functions, these genes were mapped according to the GO database by GOEAST. Furthermore, DAVID helped us locate these genes to established KEGG pathways (see Supplementary KEGGs and GOEASTs). These gene-ontology and functional-enrichment analysis showed that the plant responses to heat stress were involved in numerous biological and metabolic processes. The most significant response was the upregulation of HSPs (heat shock proteins). The accumulation of HSPs is an essential reaction to heat stress $[28,30]$.

Some low-molecular-weight HSPs, sized about 17 to $30 \mathrm{kDa}$, are categorized as smHSPs. They prevent irreversible protein inactivation and aggregation, contributing to the development of thermal tolerance. The smHSPs are not usually expressed by vegetative tissues in the absence 
of heat stress. However, the protein content detection and cDNA library screening showed that particular smHSPs could accumulate to over $1.0 \%$ of the total leaf or root cell protein. Therefore, the overexpression of smHSPs detected in this study (see Table S1) confirmed the ongoing heat shock response.

Nevertheless, what truly interests us is the HS response of light- and phytohormone-related genes. According to the functional annotation clustering data provided by DAVID and GOEAST, we found that genes that responded to heat stress were also highly enriched in a light radiation stimulus response and phytohormone signaling pathways (see Figure 1).
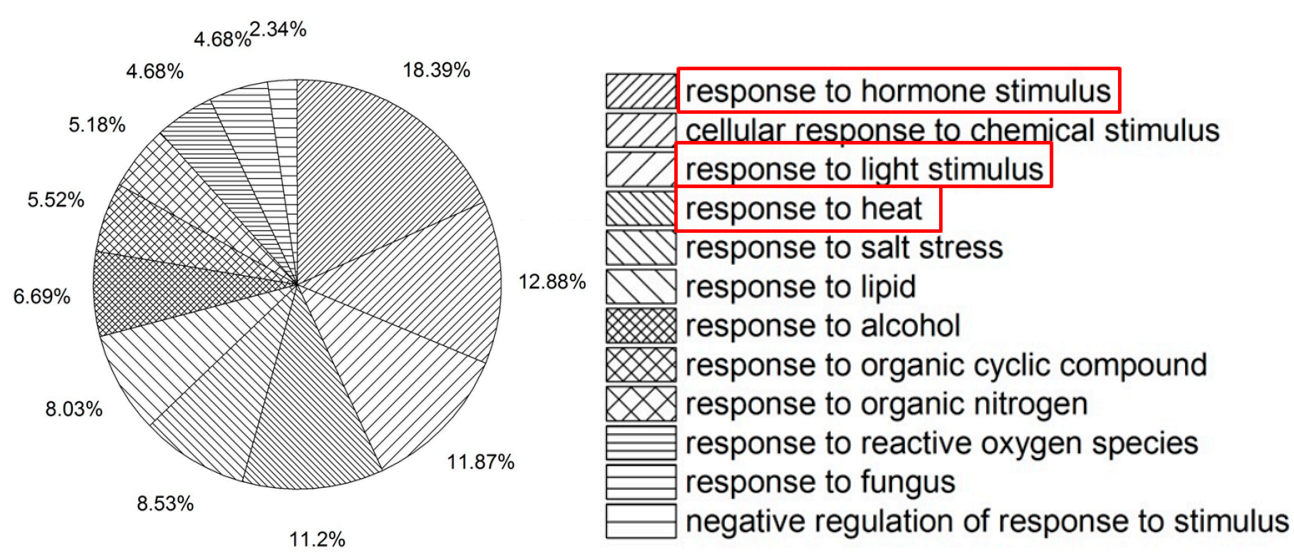

Figure 1. GO enrichment analysis of differentially expressed genes to HS treatment. GOEAST analysis reveals that the heat stress (HS)-induced differentially expressed genes are enriched into several biological processes (see original map in Supplemental KEGGS and GOEASTs). A statistics summary of biological processes on Level 4 (the 4th rank of GOEAST-biological_process, see Supplementary GOEAST GENE LIST) is presented here. On this level, $18.39 \%$ and $11.87 \%$ of the HS-induced genes are involved in hormone stimulus and light stimulus response, respectively. (Genes involving more than one category are double-counted. Red frames highlight the three "responses".)

By driving photosynthesis and carbon assimilation, light is an essential environmental factor in plant metabolism, providing a chemical energy source for the plant's life cycle [31]. Therefore, plant growth and development are dramatically regulated by environmental light [32]. Genes listed in Table S2 show that HS has a powerful impact on the expression of these "light-responsive" genes, including 14 transcription factors (see Table 1).

Table 1. Transcription factors of light signaling pathways involved in heat stress response (positive "Fold Change" means upregulated after HS; negative means downregulated). These TFs (transcription factors) indicate that light signaling pathways also respond to HS to some extent.

\begin{tabular}{ccc}
\hline No. & Gene Title & Fold Change \\
\hline 1 & TEM1 (TEMPRANILLO 1); transcription factor & -4.88839 \\
2 & RGA1 (REPRESSOR OF GA1-3 1); protein binding/transcription factor & -2.82099 \\
3 & GAI (GIBBERELLIC ACID INSENSITIVE); transcription factor & -2.27883 \\
4 & PAT1 (phytochrome a signal transduction 1); signal transducer/transcription factor & -2.02137 \\
5 & HY5 (ELONGATED HYPOCOTYL 5); double-stranded DNA binding/transcription factor & 2.29793 \\
6 & NAC2; transcription factor & 3.5822 \\
7 & MYB4; DNA binding/transcription factor & 3.60975 \\
8 & ANAC13 (Arabidopsis thaliana NAC domain protein 13); transcription factor & 3.86913 \\
9 & GA3OX1 (GIBBERELLIN 3-OXIDASE 1); gibberellin 3- 3 -dioxygenase/transcription factor & 4.73567 \\
10 & ATNFXL1 (Arabidopsis thaliana NF-X-LIKE 1); protein binding/transcription factor/zin & 5.01115 \\
11 & DREB2A; DNA binding/transcription activator/transcription factor & 16.786 \\
12 & AT-HSFA7A; DNA binding/transcription factor & 97.0821 \\
13 & AT-HSFA7B; DNA binding/transcription factor & 121.056 \\
14 & ATHSFA2; DNA binding/transcription factor & 248.051 \\
\hline
\end{tabular}


Taking DREB2 and NACs, for example, DREB2 protein, primarily activated by dehydration, high salts [33], and light [34], is reported to bind to a series responsive element. While in this study, the stress treatment is HS. Since strong radiation, high temperature, and drought are three essential ambient stimuli that happen simultaneously [35], it can be understood why the mRNA abundance of DREB2A was also increased here. The situation of NACs, another group of TFs, is similar to DREB2A. They answered the HS treatment, with light [36] and dehydration [37] as responsive elements. As for the HY5 in this table, it is a more representative element playing an important role in light signaling pathways $[4,16]$. These demonstrate the sharing of key molecular components and the continuous information communication between light and temperature signaling cascades.

Gene ontology enrichment analysis also indicated that genes related to phytohormone-mediated pathways substantially reacted to heat stress (see Table S3), including 25 transcription factors (see Table 2). It is interesting that the expressions of most TFs were suppressed. To confirm it, qPCR was conducted on several auxin-biosynthesis and transportation genes (taking ACTIN2 as an internal reference, the relative expression is obtained by comparing it with a control group $\left(23^{\circ} \mathrm{C}\right)$ ).

Table 2. Phytohormone metabolism transcription factors involved in heat stress response (positive "Fold Change" means upregulated after HS; negative means downregulated). These TFs implicate that phytohormones play essential roles in heat stress response in plants.

\begin{tabular}{|c|c|c|}
\hline No. & Gene Title & Fold Change \\
\hline 1 & MYC2; DNA binding/transcription activator/transcription factor & -11.9908 \\
\hline 2 & BT2 (BTB AND TAZ DOMAIN PROTEIN 2); protein binding/transcription factor & -8.87107 \\
\hline 3 & ERF11 (ERF DOMAIN PROTEIN 11); DNA binding/transcription factor/transcription repressor & -8.04081 \\
\hline 4 & MYB73 (MYB DOMAIN PROTEIN 73); DNA binding/transcription factor & -7.82007 \\
\hline 5 & TEM1 (TEMPRANILLO 1); transcription factor & -4.88839 \\
\hline 6 & $R A V 1 ;$ DNA binding/transcription factor/transcription repressor & -4.52717 \\
\hline 7 & ATAIB (ABA-INDUCIBLE BHLH-TYPE TRANSCRIPTION FACTOR); DNA binding/transcription factor & -4.26839 \\
\hline 8 & AS1 (ASYMMETRIC LEAVES 1); DNA binding/protein homodimerization/transcription factor & -3.37803 \\
\hline 9 & $M Y B L 2$ (Arabidopsis MYB-LIKE 2); DNA binding/transcription factor & -3.15927 \\
\hline 10 & MYB28 (MYB DOMAIN PROTEIN 28); DNA binding/transcription factor & -3.15868 \\
\hline 11 & ERF8; DNA binding/transcription factor/transcription repressor & -3.03177 \\
\hline 12 & RGA1 (REPRESSOR OF GA1-3 1); protein binding/transcription factor & -2.82099 \\
\hline 13 & AtTCP14 (TEOSINTE BRANCHED1, CYCLOIDEA and PCF (TCP) 14); transcription factor & -2.73614 \\
\hline 14 & ERF7 (ETHYLINE RESPONSE FACTOR 7); DNA binding/protein binding/transcription factor & -2.47281 \\
\hline 15 & EIL1 (ETHYLENE-INSENSITIVE3-LIKE 1); transcription factor/transcription regulator & -2.37976 \\
\hline 16 & GAI (GIBBERELLIC ACID INSENSITIVE); transcription factor & -2.27883 \\
\hline 17 & AtMYB47 (MYB DOMAIN PROTEIN 47); DNA binding/transcription factor & -2.14196 \\
\hline 18 & RAP2.7 (RELATED TO AP2.7); DNA binding/transcription factor & -2.10654 \\
\hline 19 & IAA2 (INDOLE-3-ACETIC ACID INDUCIBLE 2); transcription factor & -2.09408 \\
\hline 20 & HY5 (ELONGATED HYPOCOTYL 5); double-stranded DNA binding/transcription factor & 2.29793 \\
\hline 21 & CRF6 (CYTOKININ RESPONSE FACTOR 6); DNA binding/transcription factor & 2.87763 \\
\hline 22 & $M Y B 4 ;$ DNA binding/transcription factor & 3.60975 \\
\hline 23 & GA3OX1 (GIBBERELLIN 3-OXIDASE 1); gibberellin 3 - $\beta$-dioxygenase/transcription factor & 4.73567 \\
\hline 24 & MYB43 (MYB DOMAIN PROTEIN 43); DNA binding/transcription factor & 4.94925 \\
\hline 25 & EPR1 (EARLY-PHYTOCHROME-RESPONSIVE1); DNA binding/transcription factor & 7.39638 \\
\hline
\end{tabular}

Data in Figure 2 verify the reliability of these two independent approaches. These genes were selected because auxin orchestrates many physiological mechanisms under heat stress [38]. Consistent with previous research, the expressions of PIN3, PIN4, PIN7 [39], and AUX1 [40] were repressed, as the production of auxin production is reduced during heat stress.

For the ABP1, a protein binds the phytohormone auxin with high specificity and affinity, and its role in auxin-induced processes is still under discussion [41]. However, as a good candidate for the auxin-mediated inhibition of PIN internalization [39], the enhanced ABP1 expression and the decrease in PINs should have similar influence in auxin metabolism. This description of auxin-mediated genes is just a tiny fraction of phytohormones' significant roles in stress responses [42]. It is complicated for the interaction among different phytohormones [40], as well as the feedback mechanism between hormones and their molecular regulators [43]. In addition, the synergistic effects of ambient stimuli makes the situation more intricate [44]. 


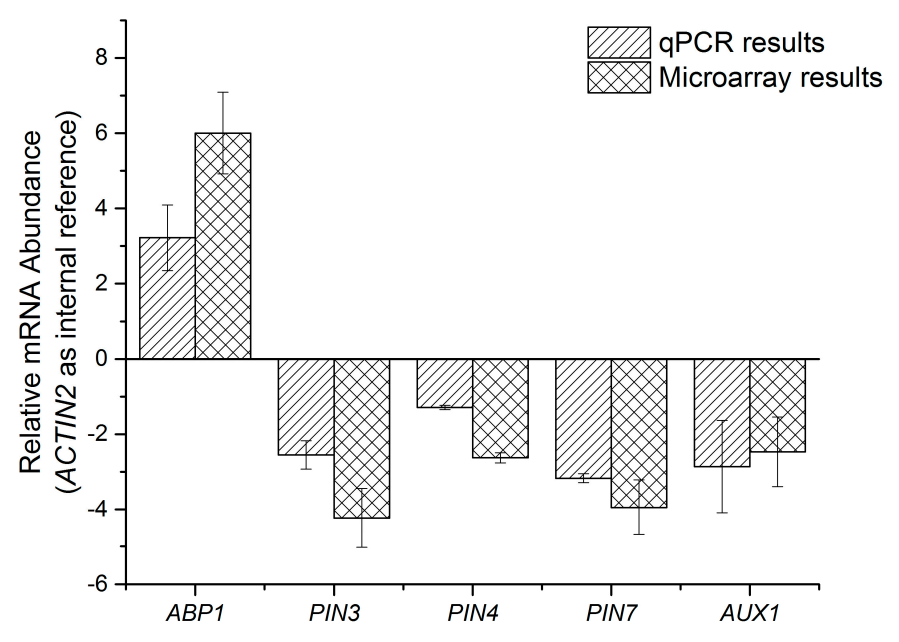

Figure 2. Relative expression of auxin-metabolism related genes. For both qPCR and microarray analysis, plants grown at $23{ }^{\circ} \mathrm{C}$ were collected as control group, and plants grown at $37{ }^{\circ} \mathrm{C}$ were collected as HS group. ACTIN2 was used as an internal reference for both assays.

Therefore, it is quite difficult to explore and confirm the function of phytochromes in a single study. However, the extensive HS response of related genes of phytohormone in this study has already effectively demonstrated their essential roles during this biological process. Moreover, considering their effective reactions to ambient changes, these phytochromes should be the common molecular components of light and temperature signaling pathways in plants, acting as bridges to deliver messages between each other.

To sum up, the treatment $\left(37^{\circ} \mathrm{C}\right.$ for $\left.30 \mathrm{~min}\right)$ applied in this study had successfully induced the transcriptomic HS response in Arabidopsis. More intriguingly, it is found that differentially expressed genes induced by high temperature are enriched in two biological processes-phytohormone metabolism and light signaling. Light- and temperature-signaling processes seem to deliver information to each other through their common molecular components, phytohormones.

Furthermore, according to the enrichment analysis, several genes induced by HS were found to be involved in map04712, in the KEGG database (see Supplementary KEGGS and GOEASTs). This shows that the HS responsive elements in this study are enriched in red and far red light perception and transduction parts. To further understand how light and temperature perception in plants intervenes with each other, a qPCR analysis was conducted.

\section{2. qPCR Analysis of Transcriptomic Response to HS under Light Conditions}

To explore how light influences the transcriptomic response to HS and the function of phyA and phyB in temperature perception, we treated plants with a series of temperature and light stimuli. Although the synergistic effects of environmental stimuli on plants have been studied previously, this is the first time that white light was divided into several wave bands before being combined with HS treatment. Then, the mRNA level (ACTIN2 adopted as internal reference) of several genes was detected by qPCR. The CCA11 $[2,3]$ and HY5 $[4,14]$ were chosen because they are important downstream factors of phyA and phyB in signaling cascades of circadian rhythms. Meanwhile, PIF4 and PIF5 were selected because they are basic helix-loop-helix (bHLH) phytochrome interaction factors, specifically interacting to the far-red light-absorbing Pfr form of phyB through conserved domains [45]. In addition, since we are curious about how phytohormone ethylene might be involved in the interaction of light and temperature stimuli on plants, the transcript level of ERF7 was also examined.

To ensure that the microarray results can be compared, the same temperature conditions ( 23 and $37^{\circ} \mathrm{C}$ ) were settled. To test whether light conditions affect HS response in plants, four light conditions were chosen: white light (WL), red light (RL), far-red light (FRL), and blue light (BL). WL was selected 
so that the qPCR and microarray results could be compared under the exact same condition. By doing this, the reliability of these two approaches was verified. RL and FRL were employed because they are effective signals in triggering the transformation of the photochrome active state [46,47]. In addition, although not too many HS-induced genes are enriched in blue light signaling, the HS + BL treatment was also conducted to plants, as a valuable comparison. Under a white light condition (see Figure 3), the variation trend and amplitude of PHYA, PHYB, PIF5, HY5, CCA1, ERF7, and PIF4 were highly consistent with microarray results, demonstrating that the outcomes of two independent experiments are credible. Making plants grow at $23^{\circ} \mathrm{C}$ and WL as the control group, it was observed that several genes responded to HS diversely under different light conditions.

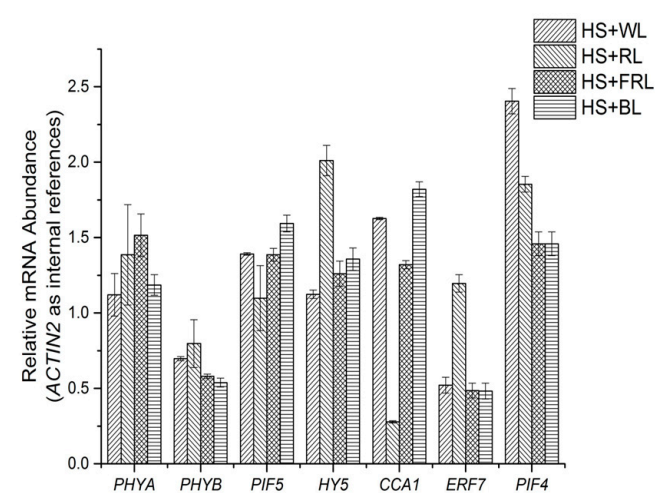

(A)

\begin{tabular}{l|r|r|r|r|} 
& BL & FRL & RL & WL \\
\hline PHYA & 1.17 & 1.5 & 1.4 & 1.12 \\
\hline PHYB & -1.81 & -1.67 & -1.25 & -1.45 \\
\hline PIF5 & 1.6 & 1.4 & 1.1 & 1.4 \\
\hline HY5 & 1.4 & 1.3 & 2 & 1.1 \\
\hline CCA1 & 1.9 & 1.4 & -3.33 & 1.6 \\
\hline ERF7 & -2 & -2 & 1.2 & -1.66 \\
\cline { 1 - 2 } PIF4 & 1.45 & 1.45 & 1.8 & 2.4 \\
\cline { 1 - 2 } & & &
\end{tabular}

(B)

Figure 3. Transcriptomic response to HS, under different light conditions treatment (compared to control plants, ACTIN2 used as internal references). Plants grown at $23^{\circ} \mathrm{C}$ are chosen as control. mRNA extraction and qPCR experiments are conducted as described in the method. HS + WL: Plants in this group are treated at $37^{\circ} \mathrm{C}$ for $30 \mathrm{~min}$, under white light. HS + RL: Treated at $37^{\circ} \mathrm{C}$ for $30 \mathrm{~min}$, under red light. HS + FRL: Treated at $37^{\circ} \mathrm{C}$ for $30 \mathrm{~min}$, under far-red light. HS + BL: Treated at $37^{\circ} \mathrm{C}$ for 30 min, under blue light. WL, white light; RL, red light; FRL, far-red light; BL, blue light. The histogram (A) shows the expressions of genes in different light conditions; the table (B) demonstrated the similarity between BL and FRL groups (green frames), and the particularity of RL group (red frames). Blue shadow means the gene expression was repressed by HS. Red shadow means enhanced.

The results of this qPCR test can be summarized as follows: (i) The expressions of both PHYA and PHYB showed no significant difference among groups; (ii) For the other genes, light seemed to disrupt their heat response substantially. The expression of PIF4 was obviously enhanced by heat only when it was under WL or RL. The expression of ERF7 stayed unchanged under RL, but suppressed severely under WL, BL, and FRL. The expression of CCA1 decreased sharply under RL. HY5 experienced a significant expression enhancement under RL; (iii) Under BL and FRL conditions, the expressions of PIF4, PIF5, ERF7, and HY5 were extremely similar and quite different from the RL situations.

Comparison among different groups shows that the active state transition of phyA and phyB led to diverse HS responses. These two phytochromes mediate plant physiological mechanism processes by switching between active and inactive forms, according to the change in ambient light conditions: Upon absorption of $\mathrm{R}$, phytochromes are converted from the biologically inactive Pr form into the active Pfr form, whereas FR irradiation converts Pfr back to Pr [48]. Experimental results in this study demonstrated that these phytochromes performed more than just light receptors. Comparison between HS + RL and HS + FRL groups directly revealed that phytochromes regulated the HS response of their downstream components by self-adjusting their own biological active states. This deduction can be further certified when we take a look at situations under blue light and far red light. It is clear that the expression of genes under BL and FRL conditions were very similar (data circled with 
green border). In the two situations, most of phyA and phyB were in the biological inactive Pr form. The difference between these two groups is whether blue light receptor cryptochromes were activated or not. The data shows that the activation of cryptochromes alone does not alter the HS responses of HY5, PIF4, and PIF5, which are downstream components of these blue light receptors [49]. Therefore, though the function of cryptochromes cannot be completely excluded, the effects of a phytchrome's active state should be dominant during plant HS perception and response.

This is not the first time that phytochromes have been reported to involve temperature perception and regulation. Karayekov et al. reported that phytochrome B mediates plant de-etiolation after the HS treatment [47]. Feng Wang et al. declared that far-red (FR) and red (R) light, perceived by phytochrome A (phyA) and phyB, positively and negatively regulate cold tolerance, respectively, in tomato (Solanum lycopersicum) [50]. The switch of the active state of phyB was also observed by Martina Legris et al., when they treated Arabidopsis with various temperatures [26]. However, this study firstly reported how these photoreceptors influence the HS responses of their downstream factors, in different light wave bands. As a light stimulus receptor, phytochromes are also crucial molecular sensor for ambient temperature perception and response. Further, the substantial effects of phyB on plant HS response were verified by the following phenotypic observation.

\subsection{Effects of HS on Different Arabidopsis Genotypes}

Recently, an increasing amount of research has shown that some light responsive-components are not exclusively activated or repressed by photostimulation [32]. Meanwhile, the transcriptomic analysis in this study also demonstrates the sharing of common components by light and temperature signaling pathways in plants.

To further verify this, HS treatment $\left(37^{\circ} \mathrm{C}\right.$ for three days) was treated on 6-day-old seedlings of col-0, phyA, and phyB. After this relatively continuous HS treatment, these genotypes exhibited different performances in morphological level: only about $44 \%$ and $40 \%$ col-0 and phyA withstood HS treatment, while more than $70 \%$ phyB stayed alive after this harshness (see Figure 4 ). In other words, the absence of phyB function seems enhanced the thermal tolerance substantially in plants.

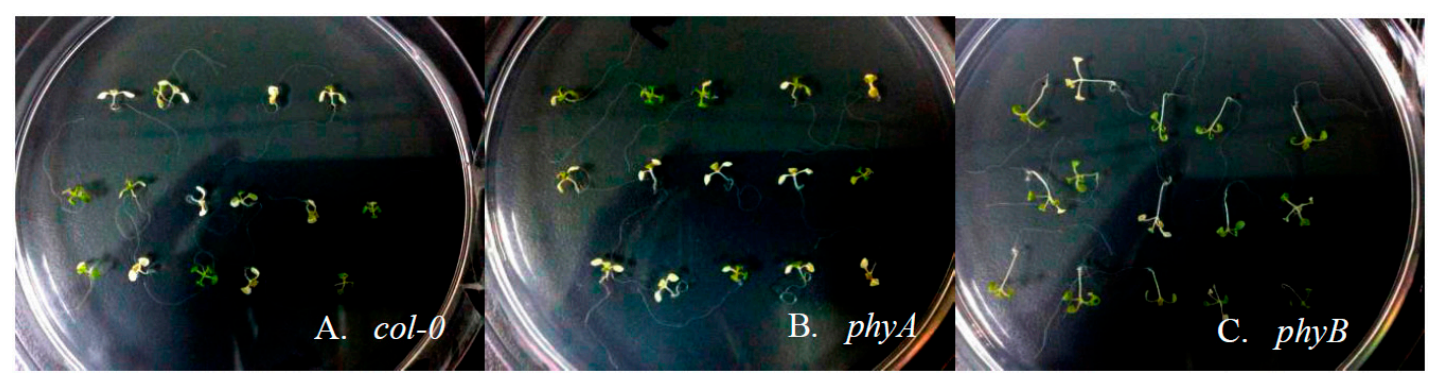

Figure 4. Survival analysis of different Arabidopsis genotypes under HS treatment. After treatment at $37^{\circ} \mathrm{C}$ for three days, about $44 \%$ and $40 \%$ col-0 and phy A seedlings still survive (see (A,B)); However, the survival rate of $p h y B$ is more than $70 \%$ (see (C)).

Based on the observation of survival individuals, it is found that root development of plants was impacted to different degrees. For col-0, the lengths of their main roots were 10-15\% shorter after 3-day HS treatment. For phyA and phyB mutants, their main roots lengths were suppressed by 20-25\%. Therefore, the HS influences on the main roots of these three Arabidopsis genotypes were similar. However, the HS responses of lateral root developments were quite diverse. The wild-type col-0 hardly developed lateral root when grown under HS, in contrast to the well-developed roots under control condition (see Figure 5A). For phyA, though the afunction of phyA already impedes its lateral development in a normal temperature condition, the HS treatment made the situation even worse: The number and length of lateral roots decreased significantly (see Figure 5B). Conversely, the lateral roots of $p h y B$ grew quite well even treated with extremely high temperature (see Figure 5C). 

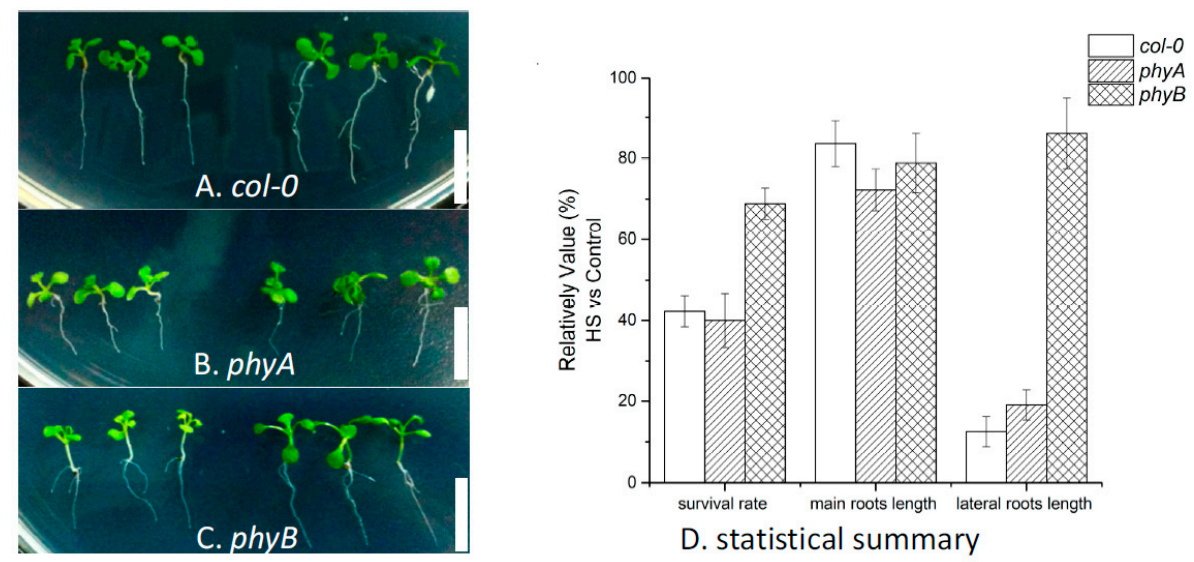

Figure 5. Root development of three genotypes of Arabidopsis (control individuals were placed on the right, treated ones left), and statistical summary for phenotype analysis. After treatment at $37^{\circ} \mathrm{C}$ for three days, the main roots lengths of all three genotypes were suppressed to a similar degree. Meanwhile, the lateral root development of col-0 and phy A seedlings are severely inhibited (see (A,B,D)). However, the lateral roots of $p h y B$ showed superior development (see $(\mathbf{C}, \mathbf{D}))$. Scale bars, $1 \mathrm{~mm}$.

These results certificated the essential function of phyB in plant HS response. This kind of phytochrome enhanced the thermal tolerance of Arabidopsis individuals by boosting their lateral root development, increasing their survival rate under long-term high temperature stress. This regulatory effect of phyB during plants HS response could be achieved by controlling its downstream components, including PIF4, PIF5, and HY5. Take PIF4 and PIF5, for instance. Mutant experiments have proved them to be crucial for Arabidopsis hypocotyl elongation, during high temperature stress [51,52]. However, as basic helix-loop-helix (bHLH) transcription factors that tightly interact with the light-activated Pfr form of phyB [53], their performance during temperature response must be substantially altered by ambient light stimulus. As another TF tightly related with plant light signaling, HY5 mutants have been reported to participate in not only the regulation of Arabidopsis hypocotyl elongation [54,55] but also the formation of stress tolerance. Nawkar et al. reported that the mutation of HY5, which negatively modulates the unfolded protein response, leads to a higher tolerance to endoplasmic reticulum (ER) stress [56]. In their study, HY5 acts as a repressor of stress-tolerance formation. This provides a clue to explaining our observation. Because of the absence of phyB function in phyB mutants, the effect of its downstream component HY5 was also abolished or disturbed to some extent during HS treatment. Accordingly, these mutants acquired a higher tolerance to ER stress caused by HS in this study, with a higher survival rate and better-developed lateral roots. This is also consistent with the qPCR results that the expression of HY5 increased more significantly in RL than in BL or FRL, indicating that biological active phyB is essential for HS-induced HY5 enhancement. In short, the deletion of phyB function by either mutation or photostimulation will dismiss the repressor role of HY 5 on plant stress-tolerance formation.. Therefore, the HS response and thermal tolerance in plants can be substantially regulated by $\mathrm{phyB}$, through its adjustment of downstream molecular components.

\section{Materials and Methods}

\subsection{Plant Materials and Growth Conditions}

Arabidopsis (Arabidopsis thaliana) genotype col-0 was used for all experiments. Sterilized seeds grew in Murashige \& Skoog solid medium within glass plates. After $72 \mathrm{~h}$ of vernalization at $4{ }^{\circ} \mathrm{C}$ in dark condition, plates were transferred to the growth camber (an ambient temperature of $23^{\circ} \mathrm{C}$, a relative humidity of approximately $70 \%$, and a photoperiod of $16 \mathrm{~h}$ of light, approximately $15.67 \mathrm{~W} / \mathrm{m}^{2}$, alternating with $8 \mathrm{~h}$ of darkness). 


\subsection{Heat Stress Treatment}

Ten-day old plants were performed with heat stress treatment through a similar method as reported elsewhere. After 10 days, seedlings plants were separated into two groups-the HS-treated group (at $37^{\circ} \mathrm{C}$ for $30 \mathrm{~min}$ ) and the control group (without HS), with three biological replications for both groups. After stress treatments, whole plant samples were collected, promptly frozen in liquid nitrogen for a subsequent microarray, and qPCR experiments.

For morphological analysis, 6-day-old seedlings were treated with a long period of HS treatment (at $37^{\circ} \mathrm{C}$ for 30 days).

\subsection{Light Conditions Adopted during HS Treatment}

For the different HS-treated groups, the high temperature is the same (at $37{ }^{\circ} \mathrm{C}$ for $30 \mathrm{~min}$ ). The light conditions are represented as follows: $\mathrm{WL}-15.62 \mathrm{~W} / \mathrm{m}^{2}, \mathrm{RL}-19.50 \mathrm{~W} / \mathrm{m}^{2}, \mathrm{FR}-19.81 \mathrm{~W} / \mathrm{m}^{2}$, and $\mathrm{BL}-4.13 \mathrm{~W} / \mathrm{m}^{2}$.

\subsection{Microarray Hybridization and Analysis}

We employed the Affymetrix GeneChip (Affymetrix, Santa Clara, CA, USA) Arabidopsis ATH1 genome array designed specifically for monitoring gene expression in Arabidopsis. Total RNA extraction and data analysis methods have been described in previous studies [15].

\section{5. $q P C R$ Analysis}

For qPCR analysis, the plants from two groups-the HS-treated group and the control group (without HS) - were sampled for RNA extraction. The RNA extraction method used in both microarrays and qPCR analysis were consistent. After being treated with Dnase I, RNA samples were used for cDNA synthesis (Thermo, Vilnius, Lithuania). Then, qPCR was performed using the LightCycler ${ }^{\circledR} 480$ SYBR Green I Master (Roche, Mannheim, Germany) with 10 pmol of each primer in $10 \mathrm{~mL}$, and the reactions were run on a LightCycler ${ }^{\circledR} 480$ (Roche). For this verification, biological triplicate col-0 samples were used. Relative expression was determined by the using of ACTIN2 (AT3G18780). As reported to be highly expressed with minimal variation across the different treatments in the microarray data [23], ACTIN2 is widely used as one stable internal reference gene in the studies of heat-induced transcriptomic response in plants. The results of qPCR were calculated and displayed using LightCycler ${ }^{\circledR} 480$ SW 1.5 software. For qPCR analysis, gene-specific primers were designed using the Primer 4 program (see primers in Table S4).

\section{Conclusions}

Light and temperature are two crucial environmental cues and stresses for plant growth and regulation. In the natural world, these two factors always act on plants simultaneously. It is the fact that germination, flowering or seed-settling happens only if a suitable ambient temperature and light intensity work together (other elements such as air humidity are also essential). Scientists have now begun to explore how light and temperature manipulates plants' physiological and morphological parameters synergistically rather than separately.

In this study, three independent experiments were carried out. The results indicate that the perception and signaling pathways of light and temperature in plants are connected.

The expression of several molecular elements, which were involved in light response, was successfully induced by HS treatment (see Table 1, microarray data). By GOEAST and KEGG analysis, they were found to be enriched in red and far red light regulated processes. This is the initial evidence that lead us to consider the potential interaction between light and temperature signaling pathways. Further, the expression of a series genes related to phytohormone metabolism answered HS treatment. Since the phytohormone regulation is so important for plants to encounter with abiotic stresses, their extensive reaction to HS is not strange. The inspiring thing is that many of these 
HS-induced phytochrome genes have been confirmed to respond to light stimulus. Therefore, although the relationship between light and temperature signaling pathway in plants has been discussed recently, the transcriptomic analysis here provides us with a more direct clue that they tightly and extensively interact with each other. Moreover, phytohormones and related elements could be potential common components of these two signaling cascades.

To further verify the deduction above, we pioneered the idea to treat Arabidopsis with HS under different light conditions. The transcriptional response examined by qPCR demonstrated that the transform of phytochromes active state has an essential influence on the HS response of their downstream factors. Besides, consistent with microarray data, the comparison among RL, FRL, and BL groups indicates that R/FR signaling pathway is more active during the HS reaction. Hence, two phytochromes, phyA and phyB, are very likely to take part in a plant's temperature perception and response through the regulation of related phytohormone factors.

At last, a morphological observation was conducted to verify the outcomes of transcriptional level. After a three-day HS treatment, phyB mutants exhibited much stronger heat-tolerance, with higher survival rates. What is more, it was also firstly reported that the HS damage of lateral development can be relieved in phyB mutants. This clearly points out the essential function of phyB during HS response and what happens when its role is absent. As discussed in phenotypic analysis, the significant role of this photoreceptor is likely to be formed by the regulation of its downstream molecular components, such as PIF4, PIF5, and HY5. By modulating the performance of these components, phyB carries out its power in HS signal perception and transduction.

Based on these three independent experiments, the existence of light and temperature signaling correlation in plants is firmly verified. It is such an exciting idea because a better understanding of the complicated HS response mechanism in plants may be obtained. Although the information can flow in other pathways, we are at least more capable of understanding how an ambient temperature signal is transduced through the relatively known light signaling cascades. Further, as a powerful photoreceptor, phyB seems to be a sensitive sensor to HS signals as well, similar to Arabidopsis and Solanum lycopersicum reported by Karayekov [47] and Wang [50], respectively. Exploring of phyB HS response might work toward finding this mysterious plant thermal sensor.

Supplementary Materials: Supplementary materials can be found at www.mdpi.com/1422-0067/18/6/1194/s1.

Acknowledgments: We thank Jian Li (Hunan Normal University, China), Weisong Pan (Hunan Agricultural University, China), Dezhi Wu, and Shengguan Cai (Zhejiang University, China) for their technical guidance and assistance.

Author Contributions: Junyi Song, conceived this study, designed and performed the experiments, analyzed the data, and wrote and revised the manuscript; Biru Hu conceived this study, and revised the manuscript; Qijun Liu analyzed the data, and revised the manuscript; Wenjian Wu directed this study, authorized the accesses to all equipment, and revised the manuscript. All authors approved the manuscript and the version to be published.

Conflicts of Interest: The authors declare no conflict of interest.

\section{References}

1. Nakashima, K.; Yamaguchi-Shinozaki, K.; Shinozaki, K. The transcriptional regulatory network in the drought response and its crosstalk in abiotic stress responses including drought, cold, and heat. Front. Plant Sci. 2014, 5, 170. [CrossRef] [PubMed]

2. Maibam, P.; Nawkar, G.M.; Park, J.H.; Sahi, V.P.; Lee, S.Y.; Kang, C.H. The influence of light quality, circadian rhythm, and photoperiod on the CBF-mediated freezing tolerance. Int. J. Mol. Sci. 2013, 14, 11527-11543. [CrossRef] [PubMed]

3. Sun, L.; Huang, L.; Hong, Y.; Zhang, H.; Song, F.; Li, D. Comprehensive analysis suggests overlapping expression of rice onac transcription factors in abiotic and biotic stress responses. Int. J. Mol. Sci. 2015, 16, 4306-4326. [CrossRef] [PubMed] 
4. Liao, W.-Y.; Lin, L.-F.; Jheng, J.-L.; Wang, C.-C.; Yang, J.-H.; Chou, M.-L. Identification of heat shock transcription factor genes involved in thermotolerance of octoploid cultivated strawberry. Int. J. Mol. Sci. 2016, 17, 2130. [CrossRef] [PubMed]

5. Vinterhalter, D.; Vinterhalter, B. Phototropic responses of potato under conditions of continuous light and subsequent darkness. Plant Growth Regul. 2015, 75, 725-732. [CrossRef]

6. McWatters, H.G.; Devlin, P.F. Timing in plants-A rhythmic arrangement. FEBS Lett. 2011, 585, 1474-1484. [CrossRef] [PubMed]

7. Hofmann, N. Cryptochromes and seed dormancy: The molecular mechanism of blue light inhibition of grain germination. Plant Cell 2014, 26, 846. [CrossRef] [PubMed]

8. Higuchi, Y.; Sumitomo, K.; Oda, A.; Shimizu, H.; Hisamatsu, T. Day light quality affects the night-break response in the short-day plant chrysanthemum, suggesting differential phytochrome-mediated regulation of flowering. J. Plant Physiol. 2012, 169, 1789-1796. [CrossRef] [PubMed]

9. Hu, X.W.; Huang, X.H.; Wang, Y.R. Hormonal and temperature regulation of seed dormancy and germination in leymus chinensis. Plant Growth Regul. 2012, 67, 199-207. [CrossRef]

10. Xin, C.; Wang, X.; Cai, J.; Zhou, Q.; Liu, F.; Dai, T.; Cao, W.; Jiang, D. Changes of transcriptome and proteome are associated with the enhanced post-anthesis high temperature tolerance induced by pre-anthesis heat priming in wheat. Plant Growth Regul. 2015, 1-11. [CrossRef]

11. Mittler, R.; Finka, A.; Goloubinoff, P. How do plants feel the heat? Trends Biochem. Sci. 2012, 37, 118-125. [CrossRef] [PubMed]

12. Hasanuzzaman, M.; Nahar, K.; Alam, M.; Roychowdhury, R.; Fujita, M. Physiological, biochemical, and molecular mechanisms of heat stress tolerance in plants. Int. J. Mol. Sci. 2013, 14, 9643-9684. [CrossRef] [PubMed]

13. Zinn, K.E.; Tunc-Ozdemir, M.; Harper, J.F. Temperature stress and plant sexual reproduction: Uncovering the weakest links. J. Exp. Bot. 2010, 61, 1959-1968. [CrossRef] [PubMed]

14. Kosova, K.; Vitamvas, P.; Urban, M.O.; Klima, M.; Roy, A.; Prasil, I.T. Biological networks underlying abiotic stress tolerance in temperate crops-A proteomic perspective. Int. J. Mol. Sci. 2015, 16, 20913-20942. [CrossRef] [PubMed]

15. Miura, K.; Furumoto, T. Cold signaling and cold response in plants. Int. J. Mol. Sci. 2013, 14, $5312-5337$. [CrossRef] [PubMed]

16. Rasmussen, S.; Barah, P.; Suarez-Rodriguez, M.C.; Bressendorff, S.; Friis, P.; Costantino, P.; Bones, A.M.; Nielsen, H.B.; Mundy, J. Transcriptome responses to combinations of stresses in Arabidopsis. Plant Physiol. 2013, 161, 1783-1794. [CrossRef] [PubMed]

17. Bita, C.E.; Gerats, T. Plant tolerance to high temperature in a changing environment: Scientific fundamentals and production of heat stress-tolerant crops. Front. Plant Sci. 2013, 4, 273. [CrossRef] [PubMed]

18. Hahn, A.; Kilian, J.; Mohrholz, A.; Ladwig, F.; Peschke, F.; Dautel, R.; Harter, K.; Berendzen, K.W.; Wanke, D. Plant core environmental stress response genes are systemically coordinated during abiotic stresses. Int. J. Mol. Sci. 2013, 14, 7617-7641. [CrossRef] [PubMed]

19. Song, J.; Liu, Q.; Hu, B.; Wu, W. Comparative transcriptome profiling of Arabidopsis Col-0 in responses to heat stress under different light conditions. Plant Growth Regul. 2015, 79, 209-218. [CrossRef]

20. Liu, H.C.; Charng, Y.Y. Common and distinct functions of Arabidopsis class A1 and A2 heat shock factors in diverse abiotic stress responses and development. Plant Physiol. 2013, 163, 276-290. [CrossRef] [PubMed]

21. Joseph, M.P.; Papdi, C.; Kozma-Bognár, L.; Nagy, I.; López-Carbonell, M.; Rigó, G.; Koncz, C.; Szabados, L. The Arabidopsis zinc finger protein 3 interferes with abscisic acid and light signaling in seed germination and plant development. Plant Physiol. 2014, 165, 1203-1220. [CrossRef] [PubMed]

22. Song, Y.; Gao, Z.; Luan, W. Interaction between temperature and photoperiod in regulation of flowering time in rice. Sci. China Life Sci. 2012, 55, 241-249. [CrossRef] [PubMed]

23. Thines, B.C.; Youn, Y.; Duarte, M.I.; Harmon, F.G. The time of day effects of warm temperature on flowering time involve PIF4 and PIF5. J. Exp. Bot. 2014, 65, 1141-1151. [CrossRef] [PubMed]

24. Chen, M.; Chory, J. Phytochrome signaling mechanisms and the control of plant development. Trends Cell Biol. 2011, 21, 664-671. [CrossRef] [PubMed]

25. Franklin, K.A.; Quail, P.H. Phytochrome functions in Arabidopsis development. J. Exp. Bot. 2010, 61, 11-24. [CrossRef] [PubMed] 
26. Legris, M.; Klose, C.; Burgie, E.S.; Rojas, C.C.R.; Neme, M.; Hiltbrunner, A.; Wigge, P.A.; Schäfer, E.; Vierstra, R.D.; Casal, J.J. Phytochrome B integrates light and temperature signals in Arabidopsis. Science 2016, 354, 897-900. [CrossRef] [PubMed]

27. Jung, J.-H.; Domijan, M.; Klose, C.; Biswas, S.; Ezer, D.; Gao, M.; Khattak, A.K.; Box, M.S.; Charoensawan, V.; Cortijo, S. Phytochromes function as thermosensors in Arabidopsis. Science 2016. [CrossRef] [PubMed]

28. Song, A.; Zhu, X.; Chen, F.; Gao, H.; Jiang, J.; Chen, S. A chrysanthemum heat shock protein confers tolerance to abiotic stress. Int. J. Mol. Sci. 2014, 15, 5063-5078. [CrossRef] [PubMed]

29. Liu, Y.; Ji, X.; Zheng, L.; Nie, X.; Wang, Y. Microarray analysis of transcriptional responses to abscisic acid and salt stress in Arabidopsis thaliana. Int. J. Mol. Sci. 2013, 14, 9979-9998. [CrossRef] [PubMed]

30. Montero-Barrientos, M.; Hermosa, R.; Cardoza, R.E.; Gutierrez, S.; Nicolas, C.; Monte, E. Transgenic expression of the Trichoderma harzianum hsp70 gene increases Arabidopsis resistance to heat and other abiotic stresses. J Plant Physiol. 2010, 167, 659-665. [CrossRef] [PubMed]

31. Rodrigues, M.A.; Bianchetti, R.E.; Freschi, L. Shedding light on ethylene metabolism in higher plants. Front. Plant Sci. 2014, 5, 665. [CrossRef] [PubMed]

32. Jumtee, K.; Okazawa, A.; Harada, K.; Fukusaki, E.; Takano, M.; Kobayashi, A. Comprehensive metabolite profiling of phya phyb phyc triple mutants to reveal their associated metabolic phenotype in rice leaves. J. Biosci. Bioeng. 2009, 108, 151-159. [CrossRef] [PubMed]

33. Lucas, S.; Durmaz, E.; Akpinar, B.A.; Budak, H. The drought response displayed by a dre-binding protein from triticum dicoccoides. Plant Physiol. Biochem. 2011, 49, 346-351. [CrossRef] [PubMed]

34. Tavakol, E.; Sardaro, M.L.S.; Shariati, V.; Rossini, L.; Porceddu, E. Isolation, promoter analysis and expression profile of Dreb2 in response to drought stress in wheat ancestors. Gene 2014, 549, 24-32. [CrossRef] [PubMed]

35. Ergen, N.Z.; Thimmapuram, J.; Bohnert, H.J.; Budak, H. Transcriptome pathways unique to dehydration tolerant relatives of modern wheat. Funct. Integr. Genom. 2009, 9, 377-396. [CrossRef] [PubMed]

36. Wang, Z.; Rashotte, A.M.; Dane, F. Citrullus colocynthis NAC transcription factors CcNAC1 and CcNAC2 are involved in light and auxin signaling. Plant Cell Rep. 2014, 33, 1673-1686. [CrossRef] [PubMed]

37. Budak, H.; Hussain, B.; Khan, Z.; Ozturk, N.Z.; Ullah, N. From genetics to functional genomics: Improvement in drought signaling and tolerance in wheat. Front. Plant Sci. 2015, 6, 1012. [CrossRef] [PubMed]

38. Qu, A.L.; Ding, Y.F.; Jiang, Q.; Zhu, C. Molecular mechanisms of the plant heat stress response. Biochem. Biophys. Res. Commun. 2013, 432, 203-207. [CrossRef] [PubMed]

39. Wabnik, K.; Govaerts, W.; Friml, J.; Kleine-Vehn, J. Feedback models for polarized auxin transport: An emerging trend. Mol. Biosyst. 2011, 7, 2352-2359. [CrossRef] [PubMed]

40. Vandenbussche, F.; Petrášek, J.; Žádníková, P.; Hoyerová, K.; Pešek, B.; Raz, V.; Swarup, R.; Bennett, M.; Zažímalová, E.; Benková, E. The auxin influx carriers AUX1 and LAX3 are involved in auxin-ethylene interactions during apical hook development in Arabidopsis thaliana seedlings. Development 2010, 137, 597-606. [CrossRef] [PubMed]

41. Chen, X.; Grandont, L.; Li, H.; Hauschild, R.; Paque, S.; Abuzeineh, A.; Rakusova, H.; Benkova, E.; Perrot-Rechenmann, C.; Friml, J. Inhibition of cell expansion by rapid abp1-mediated auxin effect on microtubules. Nature 2014, 516, 90-93. [CrossRef] [PubMed]

42. Sasaki-Sekimoto, Y.; Jikumaru, Y.; Obayashi, T.; Saito, H.; Masuda, S.; Kamiya, Y.; Ohta, H.; Shirasu, K. Bhlh transcription factors ja-associated MYC2-like 1, JAM2 and JAM3 are negative regulators of jasmonate responses in Arabidopsis. Plant Physiol. 2013. [CrossRef] [PubMed]

43. Zhang, Z.; Huang, R. Enhanced tolerance to freezing in tobacco and tomato overexpressing transcription factor terf2/leerf2 is modulated by ethylene biosynthesis. Plant Mol. Biol. 2010, 73, 241-249. [CrossRef] [PubMed]

44. Carvalho, R.F.; Campos, M.L.; Azevedo, R.A. The role of phytochrome in stress tolerance. J. Integr. Plant Biol. 2011, 53, 920-929. [CrossRef] [PubMed]

45. Leivar, P.; Monte, E.; Al-Sady, B.; Carle, C.; Storer, A.; Alonso, J.M.; Ecker, J.R.; Quail, P.H. The Arabidopsis phytochrome-interacting factor PIF7, together with PIF3 and PIF4, regulates responses to prolonged red light by modulating phyb levels. Plant Cell Online 2008, 20, 337-352. [CrossRef] [PubMed]

46. Pedmale, U.V.; Huang, S.-S.C.; Zander, M.; Cole, B.J.; Hetzel, J.; Ljung, K.; Reis, P.A.; Sridevi, P.; Nito, K.; Nery, J.R. Cryptochromes interact directly with PIFs to control plant growth in limiting blue light. Cell 2016, 164, 233-245. [CrossRef] [PubMed] 
47. Karayekov, E.; Sellaro, R.; Legris, M.; Yanovsky, M.J.; Casal, J.J. Heat shock-induced fluctuations in clock and light signaling enhance phytochrome B-mediated Arabidopsis deetiolation. Plant Cell 2013, 25, 2892-2906. [CrossRef] [PubMed]

48. Shikata, H.; Hanada, K.; Ushijima, T.; Nakashima, M.; Suzuki, Y.; Matsushita, T. Phytochrome controls alternative splicing to mediate light responses in Arabidopsis. Proc. Natl. Acad. Sci. USA 2014, 111, 18781-18786. [CrossRef] [PubMed]

49. Xu, P.B.; Lian, H.L.; Wang, W.X.; Xu, F.; Yang, H.Q. Pivotal roles of the phytochrome-interacting factors in cryptochrome signaling. Mol. Plant 2016, 9, 496-497. [CrossRef] [PubMed]

50. Wang, F.; Guo, Z.; Li, H.; Wang, M.; Onac, E.; Zhou, J.; Xia, X.; Shi, K.; Yu, J.; Zhou, Y. Phytochrome A and $\mathrm{B}$ function antagonistically to regulate cold tolerance via abscisic acid-dependent jasmonate signaling. Plant Physiol. 2016, 170, 459-471. [CrossRef] [PubMed]

51. Koini, M.A.; Alvey, L.; Allen, T.; Tilley, C.A.; Harberd, N.P.; Whitelam, G.C.; Franklin, K.A. High temperature-mediated adaptations in plant architecture require the bhlh transcription factor PIF4. Curr. Biol. 2009, 19, 408-413. [CrossRef] [PubMed]

52. Stavang, J.A.; Gallego-Bartolome, J.; Gomez, M.D.; Yoshida, S.; Asami, T.; Olsen, J.E.; Garcia-Martinez, J.L.; Alabadi, D.; Blazquez, M.A. Hormonal regulation of temperature-induced growth in Arabidopsis. Plant J. Cell Mol. Biol. 2009, 60, 589-601. [CrossRef] [PubMed]

53. Legris, M.; Nieto, C.; Sellaro, R.; Prat, S.; Casal, J.J. Perception and signalling of light and temperature cues in plants. Plant J. Cell Mol. Biol. 2017, 90, 683-697. [CrossRef] [PubMed]

54. Gangappa, S.N.; Kumar, S.V. DET1 and HY5 control PIF4-mediated thermosensory elongation growth through distinct mechanisms. Cell Rep. 2017, 18, 344-351. [CrossRef] [PubMed]

55. Srivastava, A.K.; Senapati, D.; Srivastava, A.; Chakraborty, M.; Gangappa, S.N.; Chattopadhyay, S. Short hypocotyl in white light1 interacts with elongated hypocotyl5 (HY5) and constitutive photomorphogenic1 (COP1) and promotes COP1-mediated degradation of HY5 during Arabidopsis seedling development. Plant Physiol. 2015, 169, 2922-2934. [PubMed]

56. Nawkar, G.M.; Kang, C.H.; Maibam, P.; Park, J.H.; Jung, Y.J.; Chae, H.B.; Chi, Y.H.; Jung, I.J.; Kim, W.Y.; Yun, D.-J. HY5, a positive regulator of light signaling, negatively controls the unfolded protein response in Arabidopsis. Proc. Natl. Acad. Sci. USA 2017, 201609844.

(C) 2017 by the authors. Licensee MDPI, Basel, Switzerland. This article is an open access article distributed under the terms and conditions of the Creative Commons Attribution (CC BY) license (http:/ / creativecommons.org/licenses/by/4.0/). 